\title{
PRODUCCIÓN DE BIOELECTRICIDAD EN CELDAS DE COMBUSTIBLE MICROBIANA UTILIZANDO ACIDITHIOBACILLUS FERROOXIDANS
}

\author{
PRODUCTION OF BIOELECTRICITY IN MICROBIAL FUEL CELLS USING \\ ACIDITHIOBACILLUS FERROOXIDANS
}

\author{
Daladier Castillo Cotrina' ${ }^{1}$, Carlos Tito Vargas²
}

\section{RESUMEN}

El presente trabajo tuvo como objetivo generar electricidad en celdas de combustible microbiana (MFC) utilizando células bacterianas de Acidithiobacillus ferrooxidans y en medio cultivo 9K conteniendo los sustratos. En la MFC que tuvo dos cámaras, en la cámara anódica se colocó una suspensión de $A$. ferrooxidans conteniendo el medio de cultivo $9 \mathrm{~K}$ y en la cámara catódica se colocó agua destilada y a la vez se le aireó a razón de 1 VVM. El proceso se realizó a temperatura de laboratorio. Los datos de experimentación se registraron utilizando un multímetro. Los resultados obtenidos fueron: un voltaje máximo de $330 \mathrm{mV}$ sin utilizar resistencia de corriente a los 16 días de un total de 18 días, en que duró la experimentación; así mismo se determinó un área de polarización, relacionando gráficamente la densidad de potencia versus densidad de corriente, entre los 2 y 6 días de experimentación evidenciándose en el límite superior, un valor tope más alto de la curva obtenida a los 6 días correspondiente a una densidad de potencia de $0,8094 \mathrm{~mW} / \mathrm{m} 2$ y de densidad de corriente de 2,3107 $\mathrm{mA} / \mathrm{m} 2$; y en el límite inferior, un valor tope más alto de la curva obtenida a los 10 días con una densidad de potencia de $0,0952 \mathrm{~mW} / \mathrm{m} 2$ y de densidad de corriente de 2,3214 mA/m2.

Palabras clave: bioelectricidad; celda de combustible microbiana; medio 9K, curva de polarización.

\section{ABSTRACT}

The present work aimed to generate electricity in microbial fuel cells (MFC) using bacterial cells of Acidithiobacillus ferrooxidans and in $9 \mathrm{~K}$ medium containing the substrates. In the CFM that had two chambers, a suspension of $\mathrm{A}$. ferrooxidans containing the $9 \mathrm{~K}$ culture medium was placed in the anodic chamber and distilled water was placed in the cathodic chamber and aerated at $1 \mathrm{VVM}$. The process was performed at laboratory temperature. Experiment data were recorded using a multimeter. The results obtained were: a maximum voltage of $330 \mathrm{mV}$ without using resistance of current to the 16 days of a total of 18 days, during which the experimentation lasted; Likewise, an area of olarization was determined, graphically relating the power density versus current density, between the 2 and 6 days of experimentation evidencing in the upper limit, a higher value of the curve obtained at 6 days corresponding to one power density of $0.8094 \mathrm{~mW} / \mathrm{m} 2$ and current density of $2.3107 \mathrm{~mA} / \mathrm{m} \mathrm{2}$; and at the lower limit, a higher limit value of the curve obtained at 10 days with a power density of $0.0952 \mathrm{~mW} / \mathrm{m} 2$ and a current density of $2.3214 \mathrm{~mA} / \mathrm{m} 2$.

Keywords: bioelectricity; microbial fuel cell; 9K medium, polarization curve

\footnotetext{
Doctor en Ciencias Ambientales

Docente de la Facultad de Ciencias - Universidad Nacional Jorge Basadre Grohmann - Tacna Perú

2 Msc. con mención en Gestión Ambiental

Docente de la Facultad de Ciencias - Universidad Nacional Jorge Basadre Grohmann - Tacna Perú
} 


\section{INTRODUCCIÓN}

Todas las bacterias a través de su metabolismo obtienen energía usando substratos orgánicos e inorgánicos, con el transporte de electrones en sus membranas celulares, que luego estos podrían transportarse por medio de conductores externos generando energía eléctrica en su trayecto. Este tipo de bioelectricidad es un tipo de bioenergía que se genera por acción microbiana cuando estos actúan sobre materiales orgánicos en celdas llamadas celdas de combustible microbiano. Esta bioenergía recientemente se está promoviendo.

Las investigaciones sobre la generación de bioelectricidad tienden a intensificarse cada vez más, porque es un tipo de energía renovable, no contaminante, que en el futuro junto a otras energías renovables podría reemplazar a las que son no renovables como el petróleo, el cual actualmente es el que más se utiliza y que por ser un recurso altamente contaminante $y$ encontrarse en vías de agotamiento necesita que el hombre encuentre reemplazo a esta forma de energía en la cantidad, disponibilidad y calidad suficiente.

En general la mayoría de los microorganismos no pueden ser cultivados en el laboratorio, debido a necesidades nutricionales para su metabolismo, sin embargo estas bacterias generadoras de electricidad crecen en medios de cultivo en laboratorio. Debido a ello, estos utilizan compuestos orgánicos que se encuentran en el medio, como desecho de industrias mineras por ejemplo, y los metabolizan, y que al hacerlo liberan electrones, que luego son trasladados a metales, es allí donde radica este trabajo de investigación, en la cual se puede adecuar celdas microbianas, conteniendo electrodos, capaces de canalizar los electrones generando electricidad.

\section{Principio de funcionamiento de una celda de combustible microbiano}

El principio de funcionamiento en el que se basan es el inverso al de la reacción electrolítica. El oxígeno e hidrógeno se combinan para formar agua con producción de energía eléctrica y calor. Se trata, por lo tanto, de una reacción limpia, en la que el único producto es el vapor de agua que puede ser liberado a la atmósfera sin ningún peligro para el medio ambiente. Además, del hidrógeno puro que pueda provenir de la electrólisis a partir de una fuente renovable, $u$ otras fuentes como naftas, gases licuados del petróleo, metanol, etanol, biomasa, etc., que tan solo precisarían de un tratamiento adecuado (reformado, purificación) para adaptarlos a los diferentes tipos de Pilas de Combustible.

El hidrógeno $\left(\mathrm{H}_{2}\right)$ penetra por el electrodo negativo (ánodo) y se disocia, en presencia del catalizador, en iones positivos $\mathrm{H}^{+}$y electrones. El oxígeno $\left(\mathrm{O}_{2}\right)$ procedente del aire penetra por el electrodo opuesto (cátodo) y se disocia igualmente en presencia del catalizador en iones. Los iones positivos del hidrógeno se escapan a través del electrolito en dirección al cátodo, dejando a los electrones libres en el ánodo. Si existe un camino eléctrico entre el ánodo y el cátodo los electrones lo recorrerán, produciendo corriente eléctrica. En el cátodo los iones hidrógeno, el oxígeno y los electrones se vuelven a combinar para formar moléculas de agua.

Una celda de combustible es un sistema de flujo estable, en el cual el combustible y el oxidante se suministran desde una fuente externa que provee un medio de transformar energía química en eléctrica, sin combustión y sin contaminar el aire ni el agua, en un proceso continuo y directo mediante reacciones de reducción y oxidación en presencia de un catalizador, y elimina los productos de la reacción. De manera ideal, no hay cambio en la composición química del electrolito o de ambos electrodos.

La reacción química que ocurre es isotérmica y continua. Las celdas no están limitadas por el Principio de Carnot, por lo que pueden alcanzar una mayor eficiencia teórica en la conversión de energía, mientras que las reacciones de combustión, involucran grandes variaciones de temperatura, lo cual genera energía como calor o calor y trabajo. Las pérdidas excesivas que se producen en los sistemas de conversión de energía de varias etapas pueden evitarse mediante el uso de celdas de combustible que hacen la conversión en un proceso de una sola etapa. 
Como se dijo, una reacción ocurre en la superficie de un electrodo que ioniza el combustible y manda los electrones liberados a un circuito eléctrico externo, y en la superficie del otro electrodo ocurre una reacción que recibe electrones del circuito externo que cuando se combinan con el oxidante crean iones. Los iones se combinan en el electrolito para completar la reacción total. Este último, que no es conductor eléctrico, transporta los iones entre los electrodos, para completar el circuito y continuar con el flujo de electrones.

En las celdas de combustible microbiano los microorganismos juegan un rol muy importantes estos son generadores de los electrones. Dentro de los microorganismos que se conocen están las bacterias que generan electricidad a través de unas moléculas que intervienen en este proceso. Para identificar las moléculas protagonistas de este proceso se utilizó, según Juan Pablo Busalmen, espectroscopia en el rango infrarrojo demostrando que la molécula protagonista del proceso corresponde a citocromos del tipo C. Estas son proteínas involucradas en la respiración en animales, plantas, organismos fotosintéticos y también en bacterias. A diferencia de otras bacterias que no generan electricidad, la característica distintiva de las bacterias estudiadas, es la presencia de estas proteínas en su membrana externa (Busalmen y col., 2008).

Sobre los componentes de una MFC se tiene: los materiales del ánodo y el cátodo son seleccionados en base a varias propiedades, tales como: gran área superficial, estabilidad química, biocompatibilidad (ánodo), y buena conductividad. Como material del ánodo, el carbono es preferible a los metales como el cobre ya que este último es tóxico para las bacterias. Así, el carbón de fieltro, espuma de carbón y grafito granulado han demostrado ser muy eficaces. El cátodo es generalmente del mismo material que el ánodo, aunque se ha experimentado con varias combinaciones. En algunos ensayos se utilizan catalizadores de platino para aumentar la tasa de reducción de oxígeno disuelto en el compartimento catódico. La membrana de intercambio iónico, como Nafion, juega un papel importante no solo por el propósito de transferir protones del compartimento anódico al catódico, sino también por la prevención de la introducción de oxígeno en la dirección inversa.

La composición del catolito es importante porque ha mostrado ventajas. Por ejemplo, MFC con ferricianuro ha demostrado que producen 1,5 a 1,8 veces más densidad de potencia que los que utilizan aire con platino (Oh y Logan, 2005). A su vez, el permanganato de potasio ha producido 4,5 y 11,3 veces más densidad de energía que el ferricianuro y oxígeno respectivamente (You et al., 2006). Si bien de esta manera es posible aumentar la densidad de corriente significativamente, el uso de estos agentes oxidantes no es una alternativa viable para un desarrollo económico de la tecnología, puesto que su uso es mucho más costoso que $\mathrm{O}_{2}$. Además, ni siquiera es posible su regeneración (reoxidación) usando $\mathrm{O}_{2}$ una vez agotado el poder oxidante.

Varios otros factores contribuyen a la extracción eficiente de la potencia máxima de un sistema de MFC. Estos incluyen la distancia entre los electrodos, la fuerza iónica y la temperatura. Un aumento de potencia de hasta un $85 \%$ se ha observado cuando la fuerza iónica (concentración de $\mathrm{NaCl}$ ) es variada. Dado que las MFC son aplicables sobre todo en el tratamiento de aguas residuales, el aumento de la concentración de sal de las aguas residuales es una estrategia inviable.

\section{Acidithiobacillus ferrooxidans}

Se trata de una bacteria Gram negativa de la especie Acidithiobacillus, con forma de bastón. Cuenta con un flagelo polar que le da motilidad en medios líquidos. Se reproduce por fisión binaria y no forma esporas. Esta bacteria es acidófila, (capaz de vivir en medio ácidos, $1.4 \leq$ $\mathrm{pH} \leq 6.0$ ); mesófila (vive a temperaturas moderadas, $20{ }^{\circ} \mathrm{C} \leq \mathrm{T}^{\circ} \leq 35{ }^{\circ} \mathrm{C}$ ); aerobia y anaerobia facultativa, en ambiente aerobio utiliza oxígeno como aceptor de electrones y en condiciones anaerobias utiliza ión férrico como aceptor; qumiolitótrofa, esta bacteria es capaz de oxidar ión ferroso y compuestos reducidos de azufre en soluciones de ácido sulfúrico en presencia de oxígeno. La energía que obtiene de la oxidación la usa para fijación de dióxido de carbono, crecimiento y mantenimiento celular. (Diaz, 2007)

Esta especie (Kelly an d Wood, 2 000) es una de las más importantes del género Thiobacillus 
y ha sido muy estudiada por su reconocida capacidad de oxidar aeróbicamente $\mathrm{Fe}^{2+} \mathrm{y}$ compuestos reducidos de azufre (Meruane and Vargas, 2003; Eneroth and Koch, 2004; Cabrera et al., 2005; Daoud and Karamanev, 2006). Al igual que las anteriores, tienen forma de bacilos, con dimensiones que varían entre entre 0.3 y $0.6 \mu \mathrm{m}$ de diámetro y de 1 a $4 \mu \mathrm{m}$ de largo. Son quimiolitotróficas, es decir, tanto el carbono como la energía la obtienen a partir de fuentes inorgánicas. La mayoría de las cepas tienen un mecanismo de respiración aeróbica, aunque se han reportado algunas cepas facultativas. Otras especies de este género son $T$. thioparus, $T$. denitrificans y $T$. thiooxidans.

\section{Taxonomia de Acidithiobacillus ferrooxidans \\ Dominio: BACTERIA \\ Reino: EUBACTERIA \\ Filo: PROTEOBACTERIA \\ Clase: GAMMAPROTEOBACTERIA Orden: ACIDITHIOBACILLALES \\ Familia: ACIDITHIBACILLACEAE \\ Género: Acidithiobacillus \\ Especie: A. ferrooxidans}

\section{MATERIALES Y MÉTODO}

1. Preparación del medio de cultivo $9 \mathrm{~K}$ (Silverman y Lundgren, 1959)

A través de sus componentes se procedió a preparar el medio $9 \mathrm{~K}$

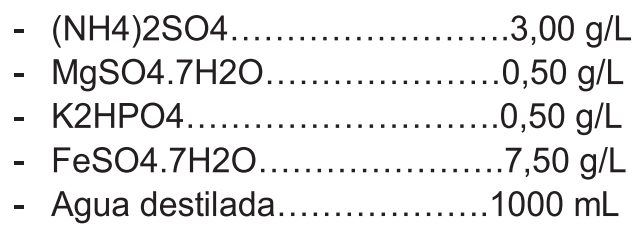

La preparación de este medio de cultivo se realizó pesando y disolviendo cada uno de los componentes químicos en el agua destilada.

Seguidamente al preparado se acidifico el medio $9 \mathrm{~K}$ a pH de 2 con H2SO4 10N, y al termino del mismo no es necesario esterilizar el medio de cultivo.

\section{Obtención y masificación de microorganismos}

- La cepa del microorganismo con que se trabajó fue $A$. ferrooxidans presentes en los lixiviados de rocas, que tengan capacidad de generar electrones, y aisladas anteriormente los cuales fueron cedidos por el laboratorio de Micología.

- Para la masificación de la cepa A. ferrooxidans, en primer lugar se activó el microorganismo por la técnica de siembra de medio líquido a medio líquido en tubo de ensayo de $10 \mathrm{~mL}$, conteniendo el medio $9 \mathrm{~K}$, al cual se le homogenizó periódicamente.

- Se llevó a incubar a temperatura de $30^{\circ} \mathrm{C}$ por 10 dias, y al terminar el crecimiento y estar en su fase de crecimiento logarítmica, se traspasó a un matraz de 50 $\mathrm{mL}$ conteniendo el medio $9 \mathrm{~K}$ y en las mismas condiciones de temperatura y a la cual se le insufló aire.

Finalmente, todo el contenido del matraz con microorganismos que se multiplicaron se trasladaron a una de las cámaras de la MFC (cámara anódica), la cual debe contener $200 \mathrm{ml}$ de medio de cultivo 9K.

3. Puesta en marcha de la celda de generación de electricidad

- Una vez colocado los microorganismos en la cámara anódica, y agua destilada estéril en la cámara catódica, ambas se taparon.

- Las tapas que contienen (en la cara interna) electrodos de grafito suspendidos y sumergidos en los medios líquidos (9K y agua destilada respectivamente) y de ellas sobresalieron (en la cara externa) un cable que unieron ambas cámaras.

- Además en la parte inferior de ambas cámaras estuvieron unidas por uniones transversales a cada cámara. $Y$ a la vez sus contenidos estuvieron separados por una membrana de intercambio protónico $(\mathrm{H}+)$. Y al mismo tiempo, la cámara catódica se aireó (oxigenación).

- Con lo cual se dio inicio a la generación de electricidad. 
Tabla 1. Características iniciales de la MFC utilizada en el experimento.

\begin{tabular}{|l|c|c|}
\hline Cámara (celda) & Anódica & Catódica \\
\hline Temperatura & $26^{\circ} \mathrm{C}$ & $26^{\circ} \mathrm{C}$ \\
\hline $\mathrm{pH}$ & 2 & 7 \\
\hline A. ferrooxidans & $0,4 \%$ & - \\
\hline Aireación & - & $1 \mathrm{VVM}$ \\
\hline Medio de cultivo & $9 \mathrm{~K}$ & - \\
\hline
\end{tabular}

Fuente: elaboración propia

4. Medición de los parámetros de evaluación de electricidad generada en la MFC

- Se midió periódicamente, (día), el potencial "E" (voltaje) de corriente discontinua "DC" generado en la MFC utilizando un multímetro digital PRASEK Premium PR-75". Estas mediciones se hicieron de mayor a menor voltaje, para evitar dañar el equipo.

- En la medición de voltaje, se colocó una de las dos puntas de cables del multímetro (cable negro, negativo) "COM" sobre el alambre que provino del ánodo de la MFC y la segunda (cable rojo, positivo) del multímetro sobre el alambre que provino del cátodo de la MFC. Esto permitió que en el multímetro se registrara y se hiciera lectura del potencial en milivoltios (mV). Este registro y lectura se hizo para cada medición sin colocar (0) y colocando resistencias de 10, 20, 50, 200, 500, 1000, 2000, 10000 y 40000 en diferentes momentos paralelo entre los cables externos del cátodo y ánodo de la MFC.

- Se calculó la intensidad de corriente, I (Amperios), usando la fórmula de la ley de Ohms $\left(I=V \cdot R^{-1}\right)$, donde $V=$ voltaje, $y$ $\mathrm{R}=$ resistencia. Para cada valor de potencia obtenida y de resistencia utilizada, se obtuvo un valor de intensidad de corriente.

- Se determinó la densidad de corriente, $\boldsymbol{j}$ (A . $\mathrm{m}^{-2}$ ), empleando la fórmula $j=\mid \mathrm{S}^{-1}$; donde $\mathrm{S}$ (área en $\mathrm{m}^{2}$ del electrodo del ánodo) para cada valor de intensidad de corriente, I, calculada con los datos anteriores.

- Se estableció la densidad de potencia, Pd $\left(\mathrm{mW} \cdot \mathrm{m}^{-2}\right)$, empleando $\mathbf{P d}=\mathrm{IVS}^{-1}$. para cada valor de intensidad de corriente y de potencia obtenida.

- Se determinó la curva de polarización graficando los valores de densidad de potencia versus los de densidad de corriente para cada tiempo de evaluación (días).

\section{RESULTADOS}

1. medios de cultivo antes y después de la siembra del microorganismo

Figura 1. Medio de cultivo 9K en la masificación de bacterias $A$. ferrooxidans, a y c sin bacteria; b y d con crecimiento microbiano.

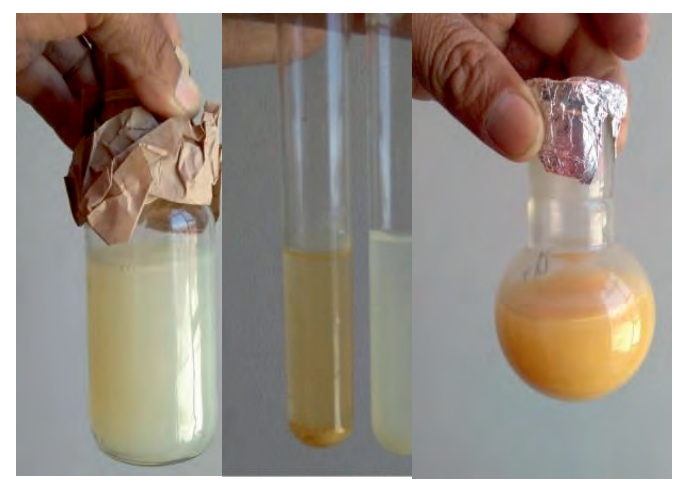

\section{Puesta en marcha de la experimentación}

Figura 2. Sistema de la celda de combustible microbiana utilizada en el experimento.

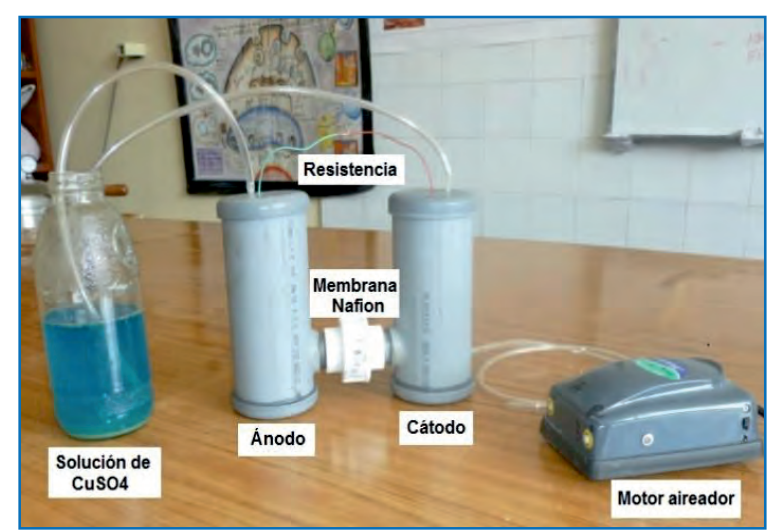

Fuente: elaboración propia

3. Biolectricidad generada en la MFC y caracterización de curva de polarización 
Tabla 2. Valores de potencial de electricidad registrado en la MFC

\begin{tabular}{|c|c|}
\hline $\mathbf{t}(\mathbf{h})$ & $\mathbf{m V}$ \\
\hline 0 & 70 \\
\hline 1 & 70 \\
\hline 2 & 73 \\
\hline 3 & 102 \\
\hline 4 & 127 \\
\hline 5 & 130 \\
\hline 6 & 130 \\
\hline 7 & 145 \\
\hline 8 & 170 \\
\hline 9 & 180 \\
\hline
\end{tabular}

\begin{tabular}{|c|c|}
\hline $\mathbf{t}(\mathbf{h})$ & $\mathbf{m V}$ \\
\hline 10 & 190 \\
\hline 11 & 190 \\
\hline 12 & 210 \\
\hline 13 & 210 \\
\hline 14 & 240 \\
\hline 15 & 300 \\
\hline 16 & 330 \\
\hline 17 & 320 \\
\hline 18 & 220 \\
\hline
\end{tabular}

Figura 3. Curva de valores de potencial de electricidad versus el tiempo de generación de electricidad registrado en la MFC.

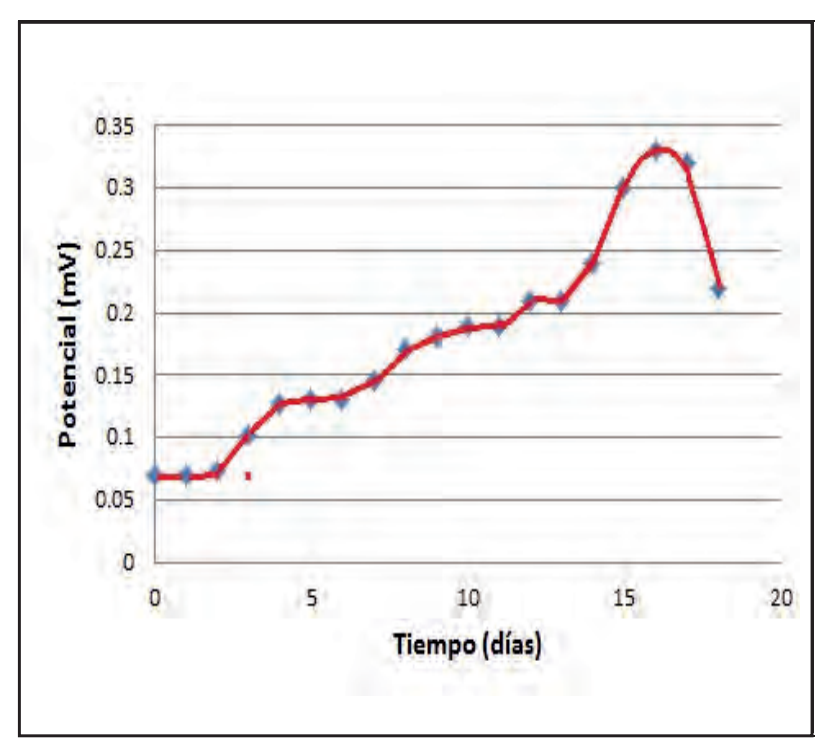

Fuente: elaboración propia

Tabla 3. Valores máximos de Potencia (E), Intensidad corriente (I), Densidad de corriente $(\mathrm{J})$ y Densidad de potencia $(\mathrm{Pd})$ a determinados valores de Resistencia (R) y Tiempo ( $T$ ) de experimentación en la MFC.

\begin{tabular}{|c|c|c|c|c|c|}
\hline & $\begin{array}{l}\text { Tiempo } \\
\text { ( días ) }\end{array}$ & $\begin{array}{c}E \\
(v)\end{array}$ & (A) & $\begin{array}{c}J \\
\left(m A / m^{2}\right)\end{array}$ & $\begin{array}{c}\text { Pd } \\
\left(\mathrm{mW} / \mathrm{m}^{2}\right)\end{array}$ \\
\hline & o & 0,0952 & $\begin{array}{c}1.14 E- \\
5\end{array}$ & 2,4462 & 0,6256 \\
\hline \multirow[t]{2}{*}{ R (ohmio) } & & 10000 & 10 & 10 & 40 \\
\hline & 2 & 0,389 & $\begin{array}{c}1,09 E- \\
5\end{array}$ & 2,2037 & 0,8094 \\
\hline \multirow[t]{2}{*}{ R (ohmio) } & & 40000 & 200 & 10 & 40 \\
\hline & 4 & 0,209 & $\begin{array}{c}1,08 E- \\
5\end{array}$ & 2,3107 & 0,2336 \\
\hline \multirow[t]{2}{*}{ R (ohmio) } & & 40000 & 200 & 200 & 40000 \\
\hline & 6 & 0,389 & $\begin{array}{c}1,08 \mathrm{E}- \\
5\end{array}$ & 2,3107 & 0,8094 \\
\hline \multirow[t]{2}{*}{ R (ohmio) } & & 40000 & 200 & 200 & 40000 \\
\hline & 8 & 0,169 & $\begin{array}{c}1,08 E- \\
5\end{array}$ & 2,3000 & 0,1528 \\
\hline \multirow[t]{2}{*}{ R (ohmio) } & & 40000 & 200 & 200 & 20 \\
\hline & 10 & 0,11 & $\begin{array}{c}1,09 E- \\
5\end{array}$ & 2,3214 & 0,0952 \\
\hline \multirow[t]{2}{*}{ R (ohmio) } & & 40000 & 200 & 200 & 10000 \\
\hline & 12 & 0,226 & $\begin{array}{c}1,09 \mathrm{E}- \\
5\end{array}$ & 2,3214 & 0,2732 \\
\hline \multirow[t]{2}{*}{ R (ohmio) } & & 40000 & 200 & 200 & 40000 \\
\hline & 14 & 0,2310 & $\begin{array}{c}1,09 E- \\
5\end{array}$ & 2,3214 & 0,2854 \\
\hline R (ohmio) & & 40000 & 200 & 200 & 40000 \\
\hline
\end{tabular}

Fuente: elaboración propia 
Figura 4: Curva de polarización. Relacionando densidad de potencia ydensidad de corriente.
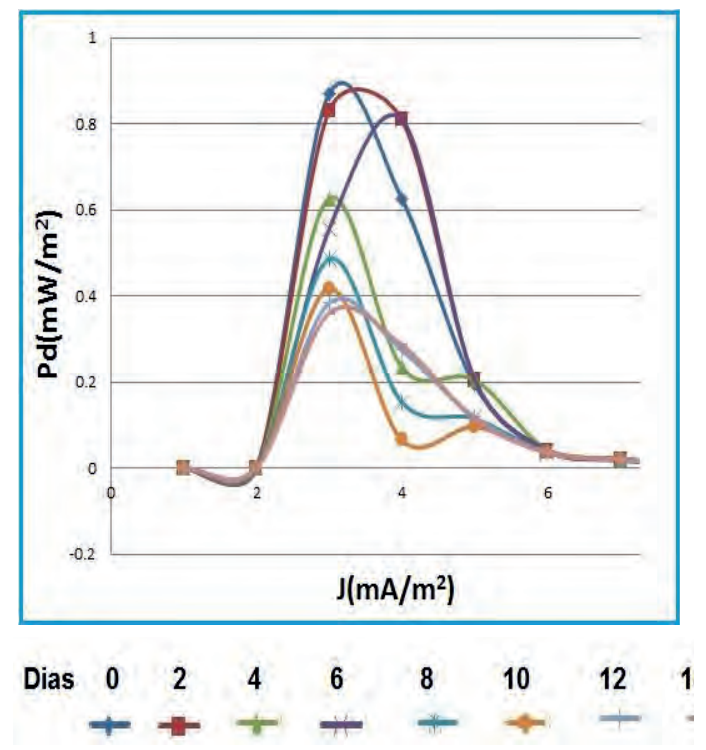

Fuente: elaboración propia

\section{DISCUSIÓN}

En el proceso de generación de electricidad a través de la MFC, utilizando un ánodo, un cátodo y una membrana permeable de protones, en la cámara anódica las bacterias de A. ferrooxidans oxidan el combustible (medio 9K) generando electrones y protones, estos protones y electrones se transfieren al compartimiento catódico, los protones pasan a través de la membrana catiónica, mientras que, los electrones se mueven a través del circuito externo, generando de este modo corriente eléctrica. Se realiza la reducción en el compartimiento catódico, y esta se da por el oxígeno suministrado por aireación a través de un motor externo. En cuanto a los electrones estos requieren de un "acarreador" que puedan trasladar los electrones desde las células hacia los electrodos, a través de los pilis y otras estructuras hacia el electrodo del ánodo y luego hacia el cátodo por un alambre conductor, generándose energía en forma de electricidad.

El voltaje obtenido en este proceso fue de 330 $\mathrm{mV}$ como promedio más alto y $73 \mathrm{mV}$ como el valor más bajo, ver cuadro 2 y figura 3 , estos resultados fueron mayores a los encontrados por Sharma \& Bulchandani, 2011, y Castillo \& Tito, 2012, que 170 y $151 \mathrm{mV}$ respectivamente, estos resultados dependieron de la homogenización del medio de cultivo porque sus componentes en suspensión tienden a sedimentar en la celda y del agotamiento del mismo. En cuanto a la baja cantidad de electricidad generada por este sistema se puede deber a pérdidas óhmicas, por activación de las células y por disminución del substrato según Saavedra, 2012 y Logan, 2008.

Con los datos de potencial (E) utilizando resistencias, se obtuvo una curva de polarización, para caracterizar la corriente en función de potencial (Tabla 3) (figura 4), por lo general se utilizó la parte superior de la curva, de polarización, registrándose al inicio (0 días) un valor de $62561 \mathrm{~mW} / \mathrm{m}^{2}$, este valor fue aumentado con el pasar de los días hasta llegar a un máximo de potencia de $0,8094 \mathrm{~mW} / \mathrm{m}^{2}$ al día 6 , y que luego esta potencia fue disminuyendo hasta $0.2854 \mathrm{~mW} / \mathrm{m}^{2}$ al día 14 . Esta tendencia de declinación de la curva de polarización, se debe, al igual que en el voltaje, a pérdidas óhmicas que se relaciona con la resistencia al flujo de electrones por parte del electrodo, también a las conexiones que se realizaron en los electrodos y la distancia entre los electrodos En este trabajo las bacterias de A. ferrooxidans produjeron las reacciones de óxido-reducción, para que se realice la transferencia de electrones hacia los electrodos, este compuesto puede estar en la superficie de las células. Otro aspecto que se tendría que tomar en cuenta es el uso de mediadores solubles para transferir electrones desde las células bacterianas hacia el electrodo Sharma \& Bulchandani, 2011.

\section{CONCLUSIONES}

- Haciendo uso de la celda de combustible microbiana se obtuvo un voltaje máximo de $330 \mathrm{mV}$ sin utilizar resistencia de corriente (asumiendo el valor de la resistencia igual a cero) empleando células bacterianas de $A$. ferrooxidans y medio de cultivo líquido $9 \mathrm{~K}$, a temperatura ambiente, en día 16.

- Se obtuvo un valor máximo de intensidad de corriente, $1,09 \times 10^{-5}$ y densidad de corriente, 0,8094 y densidad de corriente de 0,8094 todos al día 2 y 6 , y con $40000 ; 200$ y 40 ohmios respectivamente.

- Se determinó un área de polarización, relacionando gráficamente la densidad de potencia versus densidad de corriente, entre los 2 y 6 días de experimentación donde se evidenció: en el límite superior, un valor tope más alto de la curva obtenida a los 6 
correspondiente a una densidad de potencia de $0,8094 \mathrm{~mW} / \mathrm{m}^{2}$ y de densidad de corriente de $2,3107 \mathrm{~mA} / \mathrm{m}^{2}$; y en el límite inferior, un valor tope más alto de la curva obtenida a los 10 días con una densidad de potencia de $0,0952 \mathrm{~mW} / \mathrm{m}^{2}$ y de densidad de corriente de 2,3214 $\mathrm{mA} / \mathrm{m}^{2}$.

- Se determinó una curva de polarización para este proceso comprobándose que a partir del día 17, ésta empieza a tener pérdidas por disminución de sustrato o transporte de masas.

\section{REFERENCIAS BIBLIOGRÁFICAS}

BONMATI, A. and MAGRÍ, A. (2007). Tecnologías aplicables en el tratamiento de las deyecciones ganaderas: un elemento clave para mejorar su gestión. Residuos pp 46-69.

BUSALMEN, J., ESTEVE-NEÑEZ, A. Y FELIU J. (2008). Whole cell electrochemistry of electricity producing microorganisms evidence an adapttation for optimal exocellular electron transport. Environ. Sci. Technol. 2008, 42, 2445-2450. Alicante, Spain.

CHENG, S. and LOGAN, B. (2007). Sustainable and efficient biohydrogen production via electrohydrogenesis. PNAS. November 20, 2007, vol. 104, No 47 .

CASTILLO, D. Y TITO, C. (2012). Diseño y operación de una celda generadora de electricidad microbiana. Laboratorio de micología, virología y biotecnología, ESBI/FACI/UNJBG. Tacna, Perú.

ESTEVE - NUÑEZ A. (2008). Bacterias productoras de electricidad. Del sustrato a la pila de combustible. Laboratorio de Ecología Molecular. Madrid, España..
HERNANDEZ, F., PEREZ DE LOS RIOS, A., LARROSA, A., SANCHEZ, S., LOZANO, L. y GODINEZ C. (2011). Montaje y estudio de una pila de combustible microbiana para la producción de electricidad con depuración simultánea de aguas residuales. Jornadas sobre la enseñanza de las ciencias y las ingenierías. Pag. 8. 2011.

IBÁRCENA L. (2011). Estudio de la contaminación por metales pesados en los sedimentos en la Bahía de Ite, Tacna. Revista Ciencia y Desarrollo 2011; 13: 28-35.

JIANG, D., LI, B., JIA, W. and LEI, Y. (2010). Effect of Inoculum Types on Bacterial Adhesion and Power Production in Microbial Fuel Cells. Appl Biochem Biotechnol (2010)

LOGAN, B. (2005). Electricity and hydrogen production using microbial fuel cell-based technologies. Engineering Envirom. Institute. Penn State Univesity.

MARTINEZ, A. y GOSSET, G. (2011). Ingeniería metabólica de bacterias. Biotecnología V14 CS3.indd 373. Pag. 373.

MASON L.J., RICE N.M. (2002). The adaptation of Thiobacillus ferrooxidans for the treatment of nickel-iron sulphide concentrates. Minerals Engineering. 15: 795-808.

SAAVEDRA A. (2012). Producción de bioelectricidad usando celdas de combustible microbiana (MFC). Universidad Buenos Aires.

SHARMA V. K. \& BULCHANDANI B. D. (2011). Comparative study of various substrates and microorganisms in a laboratory designed microbial fuel cell. Int. J. of Buss. and Engg. Res., $4,49-59$ 